\title{
Prevalence and Correlates of Depressive Symptoms among Bangladeshi Young Adults due to COVID-19 Outbreak
}

\author{
Md. Ayatullah Khan ${ }^{1^{*}}$
}

${ }^{1}$ Development Studies Discipline, Khulna University, Khulna-9208, Bangladesh

\section{Correspondence:}

Md. Ayatullah Khan

Address: Development Studies Discipline, Khulna University, Khulna-9208, Bangladesh

Email: ayatullah.ku@gmail.com
Received: 13.08.2020,

Accepted: 22.12 .2020

https://doi.org/10.29333/jcei/9766

\begin{abstract}
A web-based cross-sectional study was conducted among 1072 Bangladeshi young adults to identify the prevalence and correlates of depressive symptoms due to COVID-19 pandemic. The 9-item patient health questionnaire (PHQ-9) was used to measure depressive symptoms. Kruskal-Wallis $\mathrm{H}$ test and ordered logistic regression were employed to identify the drivers correlated with the levels of depressive symptoms. The estimated prevalence rates of moderate to severe depressive symptoms were $54.1 \%$. Older age, residing urban area, not having stable family income, having relatives or acquaintances infected with COVID-19, being worried about educational delays or jobs, having the disturbance of daily activities, and being worried about social support were significantly associated with the levels of depressive symptoms among Bangladeshi young adults due to COVID-19 pandemic.
\end{abstract}

Keywords: COVID-19, depressive symptoms, Bangladeshi young adults

\section{INTRODUCTION}

COVID-19, officially confirmed at the end of December, 2019 in China, has quickly expanded worldwide, causing an acute respiratory problems and pneumonia with 498,912 deaths and 9,997,683 positive cases globally as of June $27,2020[1,2]$. The COVID-19 was declared as a pandemic by the World Health Organization on March 11, 2020 [3], where on March 8, 2020 in Bangladesh, the first three COVID 19 cases were found [4]. COVID-19 has become a major public health concern in Bangladesh as other countries because of its huge population and numerous factors. Around 133,978 cases (which is more than China) had been confirmed and 1,695 deaths were recorded due to COVID-19 according the official website of the Directorate General of Health Services (DGHS) of Bangladesh as of June 27, 2020 [5]. Since March 26, 2020, the Bangladeshi government has mandated a general holiday to counter COVID-19 spread [6] and all educational institutions had been shut closed since March 18, 2020 [7]. These holidays were phased out as reported cases and deaths increased. The young adults could be adversely affected, their daily actions and education have been disturbed. This could be affected their mental health. Furthermore, the nature of young adults and their mental health would potentially impact the quarantine, social and cultural differences and other restrictions due to COVID-19 pandemic [8,9]. Recent studies indicated that gender, socioeconomic status, occupation, symptoms of COVID-19, experience of COVID-19, interpersonal disputes, social contact and social support are correlated with psychological health during the COVID-19 outbreak [10-12]. However, no study was found among the Bangladeshi young adults to identify the prevalence and correlates of depressive symptoms due to COVID-19 outbreak. While designing policy measures against this significant matter of public health, the report will help to define mental health challenges and encourage the relevant authorities. The aim of this study was to identify the prevalence and correlates of depressive symptoms among Bangladeshi young adults due to COVID-19 outbreak. 
Prevalence and Correlates of Depressive Symptoms among Bangladeshi Young Adults due to COVID-19 Outbreak

Table 1. Univariate analysis of the participants about depressive symptoms $(n=1072)$

\begin{tabular}{|c|c|c|c|c|c|}
\hline \multicolumn{2}{|c|}{ Characteristics } & \multirow{2}{*}{$\begin{array}{c}\text { All n (\%) } \\
385(35.9)\end{array}$} & \multirow{2}{*}{$\begin{array}{c}\text { Mean Rank } \\
423.47\end{array}$} & \multirow{3}{*}{$\begin{array}{c}\chi^{2} \\
83.91\end{array}$} & \multirow{3}{*}{$\begin{array}{c}p \text {-value } \\
0.001^{* *}\end{array}$} \\
\hline \multirow{2}{*}{ Age (years) } & $18-24$ & & & & \\
\hline & $\geq 25$ & $687(64.1)$ & 599.84 & & \\
\hline \multirow{2}{*}{ Gender } & Male & $656(61.2)$ & 534.49 & \multirow{2}{*}{0.07} & \multirow{2}{*}{0.784} \\
\hline & Female & $416(38.8)$ & 539.67 & & \\
\hline \multirow{2}{*}{ Residence } & Urban & $532(49.6)$ & 573.96 & \multirow{2}{*}{16.20} & \multirow{2}{*}{$<0.001^{* *}$} \\
\hline & Rural & $540(50.4)$ & 499.60 & & \\
\hline \multirow{2}{*}{ Stable family income } & No & $472(44.0)$ & 619.21 & \multirow{2}{*}{63.07} & \multirow{2}{*}{$<0.001 * *$} \\
\hline & Yes & $600(56.0)$ & 471.43 & & \\
\hline \multirow{2}{*}{$\begin{array}{l}\text { Relative or acquaintance infected } \\
\text { with COVID-19 }\end{array}$} & No & $912(85.1)$ & 516.73 & \multirow{2}{*}{26.11} & \multirow{2}{*}{$<0.001^{* *}$} \\
\hline & Yes & $160(14.9)$ & 649.20 & & \\
\hline \multirow{2}{*}{$\begin{array}{c}\text { Worry about educational delays } \\
\text { or jobs }\end{array}$} & No & $284(26.5)$ & 404.98 & \multirow{2}{*}{73.06} & \multirow{2}{*}{$<0.001^{* *}$} \\
\hline & Yes & $788(73.5)$ & 583.90 & & \\
\hline \multirow{2}{*}{$\begin{array}{l}\text { Worry about future economic } \\
\text { problems }\end{array}$} & No & $96(9.0)$ & 466.25 & \multirow{2}{*}{5.68} & \multirow{2}{*}{$0.017^{*}$} \\
\hline & Yes & $976(91.0)$ & 543.41 & & \\
\hline \multirow{2}{*}{ Disturbance of daily activities } & No & $116(10.8)$ & 332.91 & \multirow{2}{*}{58.94} & \multirow{2}{*}{$<0.001 * *$} \\
\hline & Yes & $956(89.2)$ & 561.20 & & \\
\hline \multirow{2}{*}{ Worry about social support } & No & $168(15.7)$ & 420.36 & \multirow{2}{*}{29.38} & \multirow{2}{*}{$<0.001^{* *}$} \\
\hline & Yes & $904(84.3)$ & 558.08 & & \\
\hline \multirow{5}{*}{ Level of Depression } & None-minimal & $212(19.8)$ & & & \\
\hline & Mild & $280(26.1)$ & & & \\
\hline & Moderate & $236(22.0)$ & & & \\
\hline & Moderately Severe & $212(19.8)$ & & & \\
\hline & Severe & $132(12.3)$ & & & \\
\hline
\end{tabular}

$p$-value obtained from Kruskal-Wallis $\mathrm{H}$ test; ${ }^{*} p$-value $<0.05 ;{ }^{* *} p$-value $<0.01$

\section{METHODS}

The survey employed a web-based cross-sectional study of 1072 participants, recruited from Bangladeshi young adults in the time-span from May 30 to June 27, 2020. This study was conducted in accordance with the Helsinki Declaration. Study protocol was approved by an institutional review committee. Informed consent has been taken from the participants. Participants with physical troubles and not willing to participate were excluded in the study. The responses were extracted using an online self-reported survey questionnaire (using the google survey tool - Google Forms) including demographic and selected characteristics of the participants. The questionnaire was written in both Bangla and English languages. The 9-item patient health questionnaire (PHQ-9) was used to measure depressive symptoms with items scored on a 4-point Likert scale [13]. According to the scores 0-4, 5-9, 10-14, 15-19, and 20-27, the level of depression was classified in five categories respectively: minimal, mild, moderate, moderately severe, and severe. Kruskal-Wallis $\mathrm{H}$ test and ordinal logistic regression were employed to identify the drivers correlated with depression. By considering p-value $<0.05$ as statistical significance, the analysis was conducted.

\section{RESULTS}

A total of $64.1 \%$ participants were aged $\geq 25$ years and $61.2 \%$ were male. The residential estimates of the participants appeared nearly identical. Approximately, 44\% of the participants reported that their family income were not stable. Nearly, $14.9 \%$ participants claimed that their relative or acquaintance infected with COVID-19. The estimated prevalence rates of moderate to severe depressive symptoms were $54.1 \%$ (Table 1 ). In the univariate analysis, older age, residing urban area, not having stable family income, having relatives or acquaintances infected with COVID-19, being worried about educational delays or jobs, being worried about future economic problems, having the disturbance of daily activities, and being worried about social support were significantly associated with depressive symptoms with higher mean rank.

The results of the ordinal logistic regression regarding correlates of depressive symptoms are demonstrated in Table 2. After adjustment for possible drivers, older age (odds ratio $(\mathrm{OR})=2.58,95 \%$ confidence interval $(\mathrm{CI})$ : 2.03$3.28)$, residing rural area $(\mathrm{OR}=0.73,95 \% \mathrm{CI}: 0.58-0.91)$, having stable family income $(\mathrm{OR}=0.54,95 \% \mathrm{CI}: 0.42-0.68)$, having relative or acquaintance infected with COVID-19 
Prevalence and Correlates of Depressive Symptoms among Bangladeshi Young Adults due to COVID-19 Outbreak

Table 2. Estimated result of the ordered logit model on the correlates of depressive symptoms among the participants due to COVID19

\begin{tabular}{|c|c|c|c|c|}
\hline Cova & & OR & $95 \% \mathrm{Cl}$ & $p$-value \\
\hline \multirow{2}{*}{ Age (years) } & 18-24 (Ref.) & & & \\
\hline & $\geq 25$ & 2.58 & $2.03-3.28$ & $<0.001^{* *}$ \\
\hline \multirow{2}{*}{ Gender } & Male (Ref.) & & & \\
\hline & Female & 0.98 & $0.78-1.24$ & 0.912 \\
\hline \multirow{2}{*}{ Residence } & Urban (Ref.) & & & \\
\hline & Rural & 0.73 & $0.58-0.91$ & $0.007 * *$ \\
\hline \multirow{2}{*}{ Stable family income } & No (Ref.) & & & \\
\hline & Yes & 0.54 & $0.42-0.68$ & $<0.001^{* *}$ \\
\hline \multirow{2}{*}{$\begin{array}{l}\text { Relative or acquaintance } \\
\text { infected with COVID-19 }\end{array}$} & No (Ref.) & & & \\
\hline & Yes & 1.71 & $1.24-2.36$ & $0.001 * *$ \\
\hline \multirow{2}{*}{$\begin{array}{c}\text { Worry about educational delays } \\
\text { or jobs }\end{array}$} & No (Ref.) & & & \\
\hline & Yes & 2.18 & $1.64-2.91$ & $<0.001^{* *}$ \\
\hline \multirow{2}{*}{$\begin{array}{l}\text { Worry about future economic } \\
\text { problems }\end{array}$} & No (Ref.) & & & \\
\hline & Yes & 0.77 & $0.51-1.18$ & 0.240 \\
\hline \multirow{2}{*}{ Disturbance of daily activities } & No (Ref.) & & & \\
\hline & Yes & 4.08 & $2.17-6.12$ & $<0.001^{* *}$ \\
\hline \multirow{2}{*}{ Worry about social support } & No (Ref.) & & & \\
\hline & Yes & 1.93 & $1.39-2.68$ & $<0.001 * *$ \\
\hline
\end{tabular}

OR: Odd ratio. Cl: Confidence interval. Ref.: Reference. ${ }^{*} p$-value $<0.05 ;{ }^{* *} p$-value $<0.01$

$(\mathrm{OR}=1.71,95 \% \mathrm{CI}: 1.24-2.36)$, being worried about educational delays or jobs $(\mathrm{OR}=2.18,95 \% \mathrm{CI}: 1.64-2.91)$, having disturbance of daily activities $(\mathrm{OR}=4.08,95 \% \mathrm{CI}$ : 2.17-6.12), and being worried about social support (OR= 1.93, 95\% CI: 1.39-2.68) were significantly correlated with the levels of depressive symptoms.

\section{DISCUSSION}

To the author best knowledge, this is the first study to demonstrate the prevalence and correlates of depressive symptoms among Bangladeshi young adults due to COVID19 outbreak. This study reported that the estimated prevalence rates of moderate to severe depressive symptoms were $54.1 \%$. While, previous study found that mild to extremely severe depression was $57.9 \%$ among adult population in Bangladesh [10], depressive symptoms prevailed in China at $16.5 \%$ and in Japan at $11.4 \%$ among general population due to COVID-19 outbreak $[12,14]$. This study reported higher depression among Bangladeshi older adults due to COVID-19 outbreak than previous study.

After adjustment for potential drivers, older age, residing urban area, not having stable family income, having relatives or acquaintances being infected with COVID-19, being worried about educational delays or jobs, having the disturbance of daily activities, and being worried about social support were significantly associated with the levels of depressive symptoms among Bangladeshi young adults due to COVID-19 pandemic. In recent studies, however, gender, socio-economic status, education, COVID-19 symptoms and experiences, interpersonal conflicts, social interaction and social support are linked to psychological health among general and adult population due COVID-19 outbreak [1012]. Moreover, Economic and health services structures for several nations have been forced to split up in order to fight the pandemic. Additionally, pandemic-related complications including social distancing, isolation, quarantine and lockdown and the effect on community and economy, might also cause psychological mediators such as depression, worry, fear, disappointment, helplessness, loneliness and anxiety [15-17].

This study has several further limitations: the crosssectional design, convenience sampling and web-based survey. Finally, this analysis has been focused on selfreported responses regarding experiences with the COVID19 outbreak that cannot be supported by qualified data enumerators or experts.

As most of the young adults passing their times in online activities, this study suggests online consultancy, campaigns and related initiatives to combat depression due to the pandemic among Bangladeshi young adults.

Declaration of interest: The authors report no conflicts of interest.

Financial Disclosure: No financial support was received.

Acknowledgements: The author would like to recognize the kind assistance of the participants during data collection of this study. He also appreciate all the personnel for supporting the completion of this study and its data collection. 


\section{REFERENCES}

1. Bao Y, et al. 2019-nCoV epidemic: address mental health care to empower society. The Lancet, 2020. 395(10224): e37-e38. doi: 10.1016/S0140-6736(20)30309-3.

2. Worldometer. COVID-19 coronavius pandemic. 2020. Available at: https://www.worldometers.info/ coronavirus/ (Accessed: 27 June 2020).

3. Ducharme J. World Health Organization Declares COVID-19 a 'Pandemic.' Here's What That Means, in Time. 2020. Available at: https://time.com/5791661/ who-coronavirus-pandemic-declaration/

4. Hasan K, Shaon AI. Bangladesh confirms its first three cases of coronavirus, in Dhaka Tribune. 2020. Available at: https://www.dhakatribune.com/bangladesh/dhaka/ 2020/03/08/iedcr-3-affected-with-coronavirus-inbangladesh

5. Services, D.G.o.H. Coronavirus COVID-19 Dashboard, 2020. Available at: http://dashboard.dghs.gov.bd/ webportal/pages/covid19.php (Accessed: 27 June 2020).

6. Mamun S. Coronavirus: Bangladesh declares public holiday from March 26 to April 4, in Dhaka Tribune. 2020. Available at: https://www.dhakatribune.com/ bangladesh/2020/03/23/govt-offices-to-remain-closedtill-april-4

7. Shawon AA. Bangladesh closes all educational institutions till March 31, in Dhaka Tribune. 2020. Available at: https://www.dhakatribune.com/ bangladesh/dhaka/2020/03/16/govt-directs-shuttingall-educational-institutions-mach-17-to-31

8. Rubin GJ, Wessely S. The psychological effects of quarantining a city. BMJ, 2020. 368. doi: 10.1136/bmj.m313.
9. Brooks SK, et al. The psychological impact of quarantine and how to reduce it: rapid review of the evidence. The Lancet, 2020. 395(10227): 912-920. doi: 10.1016/S01406736(20)30460-8.

10. Al Banna MH, et al. The impact of the COVID-19 pandemic on the mental health of the adult population in Bangladesh: A nationwide cross-sectional study. 2020. doi: 10.1080/09603123.2020.1802409.

11. Mowbray H. In Beijing, coronavirus 2019-nCoV has created a siege mentality. Bmj, 2020: 368. doi: 10.1136/bmj.m516.

12. Wang $\mathrm{C}$, et al. Immediate psychological responses and associated factors during the initial stage of the 2019 coronavirus disease (COVID-19) epidemic among the general population in China. International journal of environmental research and public health, 2020; 17(5): 1729. doi: 10.3390/ijerph17051729.

13. Martin A, et al. Validity of the brief patient health questionnaire mood scale (PHQ-9) in the general population. General hospital psychiatry, 2006; 28(1): 7177. doi: 10.1016/j.genhosppsych.2005.07.003.

14. Ueda M, et al. Mental Health Status of the General Population during the COVID-19 Pandemic: A Crosssectional National Survey in Japan. medRxiv, 2020. doi: 10.1101/2020.04.28.20082453.

15. Xiang Y-T, et al. Timely mental health care for the 2019 novel coronavirus outbreak is urgently needed. The Lancet Psychiatry, 2020; 7(3): 228-9. doi: 10.1016/S22150366(20)30046-8.

16. Zandifar A, Badrfam R. Iranian mental health during the COVID-19 epidemic. Asian journal of psychiatry, 2020: 51. doi: 10.1016/j.ajp.2020.101990.

17. Nicola $\mathrm{M}$, et al. The socio-economic implications of the coronavirus and COVID-19 pandemic: a review. International Journal of Surgery, 2020. doi: 10.1016/j.ijsu.2020.04.018. 